\title{
Development of Human Resources in Pedagogical Activity Based on Effective Educational Practices in the Sphere of Formation of Safety Culture on Transport
}

\author{
G.S. Kamerilova, M.A. Kartavykh, E.L. Ageeva, M.A. Veryaskina* \\ Minin Nizhny Novgorod State Pedagogical University, Nizhny Novgorod, Russia \\ *Corresponding author. Email: veryaskina_ma@mail.ru
}

\begin{abstract}
The necessity and opportunities of education human resources development in the sphere of development of the culture of safety in transport are revealed, the relevance of which is determined by high risks of child road traffic injuries. The value of human resources of education is determined by their professional competence, the level of which increases in the conditions of educational practices in the system of advanced training of pedagogical staff. The educational practice is developed based on a competence approach, modular structure of content, stages of implementation based on the digital educational platform MOOC. Modern principles for the development of human resources of education are defined, which optimize the content of teachers' activities at each stage of education.
\end{abstract}

Keywords: human resources of education, educational practice, professional competence, advanced training of teachers, modular approach, digitalization of education

\section{INTRODUCTION}

Human resources present the most significant asset of the domestic educational system and the leading factor determining its progressive movement. The essence of human resources of education is revealed through the general theory of human resources (A. Maslow, F. Hercberg, D. McGregor) [1], which emphasizes their fundamental role in progressive socio-economic development. Analysis of research of human resources and problems of their management (M. Armstrong [2], L.N. Ivanov-Shvets [3], A.V. Kirianov [4], E.N. Morozov [5], N.G. Solodov [6]) allows to establish their general specificity, consisting in that they, having intelligence, can improve the situation, to self-understanding. The category «human resources» in the context of professionalpedagogical activity is considered in the works of T.A. Kaplinovich, A.J. Kibanov, N.G. Kotlyarova, Y.A. Masalova as a set of such personal qualities, which provide an important mission of education of the future citizen of the country [7-10].

Following existing state educational standards, the value of human resources of education is determined by their professional competence (V.A. Bolotov, V.V. Serikov [11], E.F. Zeer [12], J. Equal [13]), meaning the readiness and ability of the teacher to perform pedagogical activities in the logic of modern education ideas. The speed of social life defines constant «challenges» to education, the answers to which depend on the development of human resources and the enhancement of their competence. The idea of continuous education of pedagogical personnel, which should be carried out with double advance (G.M. Bordovsky), reflects the humanistic context of the era, its large-scale informatization. The educational practice of improving the skills of teachers in dynamic spheres of life, which include the development of a culture of the safety of children in transport, plays an important role. The country's actively developing road transport complex exposes a real threat to the lives of the population, and especially to its poorly protected children. The many real practices of road safety prevention used in education have made a positive contribution, but they have been dominated by traditional methods. Teachers need to improve their competence by participating in educational practices in the field of road safety of children, which is not always quickly implemented due to the distance of residence from centers of advanced training, the absence of a thematic program of practice, its incomplete compliance with the requirements of modern education. This educational practice of additional professional pedagogical education in the sphere of development of the culture of safety in transport in children for four years was carried out based on the digital educational platform MOOC at the Nizhny Novgorod State Pedagogical University named after $\mathrm{K}$. Minin at the require of the Ministry of Education and Science of the Russian Federation within the framework of the federal program «Improvement of road traffic safety in 2013-2020» [14]. It was implemented in various regions of Russia (Volgograd, Voronezh Moscow, Leningrad, Kirov regions, Far East Territory, Chechen Republic, North Ossetian Republic, etc.), and involved more than four thousand participants. 


\section{ANALYSIS OF RESEARCH PUBLICATIONS}

The analysis of practical achievements and scientific publications shows the peculiarities of human resources of education and their development. Thus, from A.K. Markova's professional competence of the teacher unites all his subject properties, which are realized through effective activity. This activity concerns the work of a teacher, including technology (pedagogical activity itself), pedagogical communication and personal qualities [15]. In the same direction «activity - communication personality» ideas about human resources of education L.M. Mitina are built [16]. I.A. Zimnaya combines all qualities of education resources into four groups: psychophysiological, abilities, personal properties, vocational-pedagogical, and subject knowledge and skills [17]. In the group of pedagogical abilities, N.V. Kuzmin justifies design-gnostic (pedagogical targeting and thinking) and reflexive-perceptual (pedagogical reflection, tact, focus), covering the main components of the educational system [18]. The structure of professional competence of human resources of education, developed by the scientific team under the leadership of V.A. Slustin, is a unity of theoretical and practical readiness for the work of the teacher, ability to relate the available level of training to new ideas, goals, ways of their achievement, understanding of the need for constant development of the creative potential [19]. An important characteristic of human resources, as N.V. Bogdan emphasizes, is their «strategic readiness», which allows to carry out professional activities in conditions of strategic changes [20], which makes the teacher's creativity (G.S. Kamerilova, M.A. Kartavykh, etc.) [21] in demand. Readiness for continuous personal and professional growth is provided, in particular, by participation in educational practices in advanced training courses providing for the mastering of new relevant competences. In literature, educational practice is interpreted in the general theory of practices (V.V. Volkov, O.V. Harhordin [22], A.A. Diakov [23]) and is interpreted as a certain experience, practice of training and communication, that is, a set of typed actions, ways to find and analyze large volumes of new information using various means; Methods of interpersonal interaction (A.N. Pichuk, Ivanov E.O., I.M. Osmolovskaya, N.A. Seliverryka, G.N. Travnikov) [2427]. Their demand increases as the cognitive process is intensified and students communicate actively. Educational practices, therefore, reflect the habits of learning in a special dynamic mode, intensive personalprofessional formation. In the context of our work, the grounds for educational practice are of interest. Thus, according to the approaches of M.V. Clarin, such issues as problematic (creation of cognitive «breaks») are included in their composition; Priority of understanding and activity; Reflexion (concerning personal position, purpose, means of activity); Self-determination in the knowledge system; Fixing the process and reflection results; activity contents [28]. The studies of I.M. Osmolovskaya justify a similar, but more detailed, position, including a description of the problem solved in practice; its didactic bases; purpose and values; Content of education, methods, forms, and means of education; idea of results; features of intersubject interaction [29].

Taking into account the trend in the development of road transport and, as a result, the risk of an increase in child road traffic injuries, it is proposed to intensify preventive activities to develop a culture of safety in transport among students, including improving the quality of teacher training taking into account educational innovations. Let us emphasize that the issues of ensuring children's road transport security are widely discussed in the literature both at the theoretical (S.S. Ahmadiyev, A.G. Babich, R.G. Ter-Gregory) [30-31] and at the practical level (A.A. Refugees [32], E.A. Bershadskaya, M.E. Bershadsky [33]. The best practices of teaching children traffic rules in Nizhny Novgorod, Leningrad, Moscow, Sverdlovsk, Smolensk regions, republics of Tatarstan, Altai, Far East Territory are known. However, issues of educational practices related to the competent format of human resources development, the use of digital support, communicative means, management and their projection on the development of advanced training projects in additional vocational education in the field of building the skills of children to participate safely in road traffic remain insufficiently investigated.

\section{PURPOSE AND OBJECTIVES OF THE STUDY}

Development and justification of the way of development of human resources in the sphere of development of the culture of safety in transport in the pedagogical activity of educational practices.

\section{RESULTS}

The competent approach, as an effective-target basis for the development of the human resource of education in the field of culture of safety in transport, implies the notion of modern teacher as an initial and creative person, possessing a need and a stable motivation for continuous personal and professional growth. In the real assessment of the dramatic situation with children's road transport safety, the teacher is ready to change the existing education in the sphere of increasing the culture of behavior on the roads in children. This requires thinking about new ideas in trends in social development and innovative educational practices; Mastering methods of implementation of modern pedagogical technologies, techniques of work in the Internet space, methods of pedagogical management. The assessment of the degree of development of the human resource is carried out through the acquisition by teachers of competences in the field of transport safety culture. They eliminate «dissonances» («gaps») between social «challenges» and educational «responses» to them. 
It should be noted that advanced training is considered as a process of professional development of a teacher in culture, meaning co-experience and co-thought attitude towards the world as a whole, surrounding people, their problems. Professional competence as an integral quality of the teacher's personality is formed in the logic of the culture of safety in transport and implies an understanding of the meaning of the forthcoming training, the values of its goals, the significance of the proposed activities, the reflection of open knowledge and the practical actions learned in the field of child safety in transport.

The stated competency format required the development of a structural model of competences proposed for development. The triad developed includes interrelated socio-legal, general professional and vocational competences. The social and legal competence, first, is based on the meaning of the activity, meaning an understanding of its social and personal significance; Secondly, the objective of the continuing education strategy; thirdly, the legitimacy of activity providing observance of legislative provisions (The Federal law of 29.12.2012 N 273-FZ (an edition of 29.07.2017) «About education in the Russian Federation», the Federal law of 10.12.1995 N 196-FZ (an edition of 26.07.2017) «About traffic safety», the Global plan of implementation of Decade of actions for the safety of traffic of 2011-2020 within Partnership of the UN on road safety; Decree of the President of the Russian Federation No. 711 of 15 June 1998 «On additional measures to ensure road safety» (ed. 01.04 .2015). The general professional competence reflects the leading innovative trends in domestic education, including, first, humanistic guidelines manifested in the individual and personal development of human resources in the process of its pedagogical activities and cultural dialogue; Secondly, the extensive and comprehensive informatization of education, which we considered earlier as a continuation of the humanist tradition [34]; Thirdly, the use of electronic educational resources and diverse communication models in the field of transport safety culture [35]. Professional competence refers to the teacher 's ability to develop programs and methodological systems to develop a culture of safety in transport for children; Effectively apply modern educational and management technologies, active and interactive methods of work in an open digital educational environment.

As a result of the educational practice, the teacher:

- Should know the role of educational activities in developing a culture of safety in transport; The importance of the practice of participation in advanced training courses in the development of relevant competencies; How to use e-learning resources for information and communication (including networking) interactions; Innovative technologies that implement a competency approach;

- Should be able to carry out information search and analysis of normative and legal support of educational practice; Independently use electronic information tools, as well as pedagogical advantages of innovative educational and management technologies.
- Should possess: methods of updating continuous vocational education at educational practices of advanced training in the field of development of the culture of safety in transport; Skills in the informed selection and targeting of e-learning resources at various stages of learning; Methods of implementation of modern pedagogical and management tools in educational practice.

Development of human resources of education in the sphere of development of the culture of safety in transport was carried out based on principles: a) competence orientation, as the leading humanistic direction of renewal of pedagogical education, in which praxiological aspect is strengthened; Representing the integration of values, knowledge, skills, modes of activity, reflection, diverse communication, as well as a deep interest in solving the current problem; B) continuity of education as an accomplished phenomenon of modernity, when mastering of new professional competences is a condition of professional success, which forms a habit of learning in a certain way, that is, in the situation of solving educational and research tasks; C) accessibility provided by remote education capabilities, as well as applied methods and algorithms for the development of skills to use new technological techniques; D) practical orientation, meaning "pragmatic turn" in pedagogical knowledge through fixed ways of discovering new knowledge and skills, rational decision-making strategy; E) personalization and activation of educational activities in the digital educational environment; F) automation to save time for routine operations; network virtual mobility. The practice was established within the capabilities of modern culture, including various meanings of educational environments characterized by various tools, skill sets, practical projects, identities.

It is considered that the implementation of the competency approach requires the development of a modular content structure. Under reasonable competences, we have developed three modules that combine the content in the sphere of development of the culture of safety in transport and methods of its absorption. The tasks of the first module «Safe Road of Childhood: Importance and Meanings» are related to the mastering of social and legal competence by teachers by working out the skills of arguing the problem, finding and analyzing its psychopedagogical and legislative grounds. The tasks of the second module «Safe Road of Childhood: Vector for Interactivity as Information Communication for Joint Action» relate to the formation of general professional competence in working in the digital educational environment, typological skills of using electronic educational resources and means of communication interaction. The tasks of the third module «Safe Road of Childhood: from Monologue to Dialogue» involve professional and specialized competence, the mastery of which implies the ability to apply modern educational and managerial technologies in the development of the culture of safety in transport, active and interactive forms and methods of work. Pedagogical advantages of modules include the possibility of personal differentiation of training and their design within the framework of created 
electronic educational and methodical complexes [36]. Each teacher moves in a personal educational trajectory, which can be built both in a logical sequence of individual modules and in a branched configuration (such as hypertext).

Educational practice at advanced training courses in the field of development of the culture of safety in transport is implemented through the following stages: motivationtargeted, information-cognitive, creative-practical, each of which contributes to the improvement of the level of competence of teachers. At the same time, according to the dominant influence, the motivation-target stage provides priority opportunities for acquisition of social and legal competence, information-cognitive - general professional, creative-practical - vocational-specialized. Accordingly, the specifics of activity content and reflection at each stage are determined. For example, at the first stage, when considering the role of a competent approach in adult education and its implementation in educational practice, a task is offered to write an essay «My idea of the professional competence of a teacher in the field of building a culture of safety in transport in children». This task not only develops the skills of creating creative products of this type but also presents a promising model of reflexive vision of the results of participation in educational practice. Practical experience of drawing up analytical certificates when working with large volumes of normative documents of the professional activity of teachers while studying legislative acts in the field of development of the culture of safety in transport is being learned. The stage begins with an introductory webinar, showing teachers with basic ideas and organization of activities, including navigation on its content, rating-plan, types of control. At the second stage, teachers improve, inter alia, skills in working with electronic educational resources, creation of electronic educational and methodological complexes and presentations (G.S. Kamerilova and others) [37]; Participate in the master class held in the digital educational environment: Indicative business portfolio of the web design studio «Organization of the teacher 's activities in the field of development of the culture of safety in transport in children». In the third stage, during the training, ideas on structural analysis of vocational-specialized competence, ways of its mastering are worked out through the development of webinars, business games, creation of a cluster of innovative technologies, project activities, solution of case-problems.

The results of training in the field of the development of the culture of safety in transport in children are related to the development of human resources of education and are characterized by the mastering of relevant competencies. Their control is carried out based on the performance of the test and creative tasks, development of the author's final project. In the course of all practice in forums, chat rooms, webinars, e-mail there is active inter-object interaction; Situational, retrospective, forward-looking reflection with analysis of the process and results achieved, problems and orientation for the future are discussed.

\section{CONCLUSIONS}

Educational practices play a major role in the development of human resources of education in the sphere of building a culture of safety in transport among students. They realize the need for teachers for continuous personal and professional growth in advanced training courses providing for the mastering of new relevant competences. Within the framework of the developed educational practice, the principles of development of human resources of education in the sphere of formation of a culture of safe behavior in transport, target guidelines in the form of a combination of socio-legal, general professional and vocational-specialized competences, the modular structure of content ensuring their mastering are justified. The process of distance education by highlighting the peculiarities of the content of teachers «activities at different stages and the use of innovative technologies is disclosed, which is considered as a way of effective and modern direction of modernization of continuous education of pedagogical personnel.

\section{ACKNOWLEDGMENT}

The work was done due to the State Contract with the Ministry of Education and Science of the Russian Federation dated June 03, 2019, № 07 .Z27.11.0005 on the «Professional Development (including at Modular Courses) Teachers of the General Education Organizations, Organizations of Additional Education and the Preschool Educational Organizations in the Sphere of Formation at Children of Skills of Safe Participation in Traffic»

\section{REFERENCES}

[1] Psychology. Fundamentals of psychology. MacGregor 's "X" and "Y" theory, URL: http://www.grandars.ru/college/psihologiya/teoriyamakgregora.html

[2] M. Armstrong, Human Resources Management Practice, 2012, 848 p.

[3] L.N. Ivanov-Shvets, A.A. Korsakov, S.L. Tarasova, Human Resources Management: Complex, 2008, 200 p.

[4] A.V. Kirianov, Concept of human resources management in the organization, Problems of Entrepreneurship in the Economy of Russia, 2005, 164 p.

[5] E.N. Morozova, Human Resources as a Factor of Sustainable Development of the Organization, Ph.D. Thesis, 2012, 194 p. 
[19] V.A. Slastenin, I.F. Isayev, E.N. Shiyanov, Pedagogy, 2002, 576 p.

management: problems and prospects (2015), Baikal Research Journal, vol. 6, no. 4. DOI : 10.17150/24116262.2015.6(4).14.

[7] T.A. Kaplunovich, Motivational strategy for development of personnel potential of education system: state policy context. Person and education, 2016. vol. 4 (49). pp. 9-14

[8] A.J. Kibanov, Human resource management of the organization, 2008, 365 p.

[9] N.G. Kotlyarov, Human resource development by organization by methods of management and education (2012), Journal of South Ural State University. Series: Education. Pedagogical sciences, vol. 41, pp. 116-124

[10] Y.A. Masalov, Quality of human resources as an object of management in the system of higher education (2016), News of the Irkutsk State Economic Academy, vol. 26, № 1, pp.107-114.

[11] V.A. Bolotov, V.V. Serikov, Competency model: from idea to educational program (2003), Pedagogy, vol. 10, pp. 8-14.

[12] E.F. Zeer, Trends in modernizing vocational education, Vocational education. Capital, 2016, vol. 10, pp. 15-21

[13] J.C. Raven, Competence in modern society: identification, development and realization, 2002, 400 p.

[14] M.A. Kartavykh, G.S. Kamerilova, Conceptual basis of advanced training of teaching staff in the field of prevention of child road traffic injuries in the light of modern directions of state educational policy (2017), Problems of modern pedagogical education, vol. 57-9, pp. 172-179.

[15] A.K. Markova, Psychological analysis of teacher 's work. Professional competence of the teacher, Pedagogical psychology, 2008, 471 p.

[16] L.M. Mitina, Personal and professional development of the teacher: strategies, resources, risks, 2018, 456 p.

[17] I.A. Zimnyaya, Pedagogical Psychology, 2010, 448 p.

[18] N.V. Kuzmina, Professionalism of the teacher and master of industrial training, 1990, 119 p.
[20] N.V. Bogdan, Development of a program of human resources development in higher education based on the strategic map (2014), Journal of South Ural State University. Series: Education. Pedagogical sciences, vol 6 (3), pp. 12-18.

[21] Kamerilova, G.S., Kartavykh, M.A., Ageeva, E.L., Gordeeva, I.A., Veryaskina, M.A. Development of Professional Creativity of Teachers in the System of Professional Safety Culture of Children in Transport (2020) Lecture Notes in Networks and Systems, 91, pp. 446-451.

[22] V.V. Volkov, O.V. Harhordin, Theory of Practice, 2008, 297 p.

[23] A.A. Diakov, Practice as a subject of social and philosophical discourse, Journal of Volga academy of public service, vol 3, 2011, pp. 208-213.

[24] A.N. Pinchuk, Educational practices in the conceptual field of sociology, Scientific potential: the work of young scientists, vol. 4, 2016, pp. 321-331.

[25] E.O. Ivanov, I.M. Osmolovskaya, Problem of didactic analysis of innovative educational practices, Education and society, vol. 4(105), 2017, pp. 34-39.

[26] N.A. Seliverstova, Educational Practices, Sociology of Youth. Electronic encyclopedia. URL: http://soc-mol.ru/encyclopaedia/youth/278obrazovatelnye-praktiki.html

[27] G.N. Travnikov, Educational Practice in the System of Pedagogical Activity, Scientific and Practical Journal «Humanization of Education», vol. 3, 2009, pp.53-58.

[28] M.V. Clarin, Innovative Learning Models: World Experience Research. Monograph, 2016, 640 p.

[29] I.M. Osmolovskaya, Innovative educational practices in the educational space of the school,

Domestic and foreign pedagogy, vol. 3(50), 2018, pp. 120-131.

[30] R.Sh. Ahmadiyev, M.G. Belugin, Formation of competence of transport-safe personality for schoolchildren (2016), Kazan Pedagogical Journal, vol. 4(117), pp. 24-29.

[31] A.G. Babich, R.G. Ter-Grigoryantz, Theoretical and methodological approaches to monitoring of 
[35] G.S. Kamerilova, M.A. Kartavykh, E.L. Ageeva, I.A. Gordeeva, N.I. Astashina, E.M. Ruban, Communicative teaching models: The formation of the professional pedagogical competence among health and safety school teachers (2018) Espacios, 39 (29), 7 p.

[36] M. Kartavykh, G.S. Kamerilova, Scientific and methodological support of additional professional programs of advanced training of teaching staff in the field of formation of skills of safe participation in road traffic in children (2018), Vestnik of Minin university University, vol. 6. No. 1. https://doi.org/10.26795/23071281-2018-6-1-3

[37] G.S. Kamerilova, O.N., Mednikova, O.A.Vlasova, G.A. Kostenko, Electronic presentations in the information and communication technology system of life safety training (2017), Azimuth of scientific research, vol. № 4 (21), pp.81-84. 